\title{
Identificação por PCR dos alelos-S associados à compatibilidade gametofítica em ameixeira japonesa
}

\author{
Daniela De Conti $^{(1)}$, Mirian de Farias Ribeiro(2), Maria do Carmo Bassols Raseira( ${ }^{(3)}$, \\ José Antônio Peters ${ }^{(2)}$ e Valmor João Bianchi(2)
}

\begin{abstract}
(1)Universidade Federal de Santa Catarina, Centro de Ciências Agrárias, Departamento de Fitotecnia, Caixa Postal 5040, CEP 88034-001 Florianópolis, SC. E-mail: danideconti@yahoo.com.br (2)Universidade Federal de Pelotas, Instituto de Biologia, Departamento de Botânica, Caixa Postal 354, CEP 96010-900 Capão do Leão, RS. E-mail: mirianfribeiro@yahoo.com.br, japeters1@hotmail.com, valmorjb@yahoo.com ${ }^{(3)}$ Embrapa Clima Temperado, Rodovia BR 392, Km 78, Caixa Postal 403, CEP 96001-970 Pelotas, RS. E-mail: maria.bassols@embrapa.br
\end{abstract}

\begin{abstract}
Resumo - O objetivo deste trabalho foi identificar e caracterizar molecularmente os alelos-S de cultivares de ameixeira japonesa e verificar a compatibilidade gametofítica entre estes. Foram utilizados dois pares de iniciadores específicos na amplificação dos alelos via PCR, em 18 cultivares: Pluma 7, Gulf Rubi, Blood Plum, Wickson, América, Santa Rosa, Rosa Mineira, Estrela Púrpura, Amarelinha, The First, Harry Pieckstone, Santa Rita, Seleção 16, Seleção A26 (Burbank), Seleção 21, Seleção 19, Methley e Simka. As condições da PCR e as combinações de oligonucleotídeos iniciadores utilizadas permitiram a identificação de alelos-S nas cultivares, bem como a indicação dos polinizadores mais compatíveis. As cultivares América e Santa Rosa, bem como Blood Plum, Wickson, Rosa Mineira, Estrela Púrpura e Seleção 21 apresentam incompatibilidade total entre si, por compartilharem os mesmos alelos.
\end{abstract}

Termos para indexação: Prunus salicina, autoincompatibilidade gametofítica, S-RNase.

\section{Identification by PCR of S-alleles associated with gametophytic compatibility in Japanese plum}

\begin{abstract}
The objective of this work was to molecularly identify and characterize the S-alleles of Japanese plum cultivars and to verify the gametophytic compatibility between them. Two pairs of specific primers were used for allele amplification by PCR in 18 cultivars: Pluma 7, Gulf Rubi, Blood Plum, Wickson, América, Santa Rosa, Rosa Mineira, Estrela Púrpura, Amarelinha, The First, Harry Pieckstone, Santa Rita, Seleção 16, Seleção A26 (Burbank), Seleção 21, Seleção 19, Methley, and Simka. PCR conditions and oligonucleotide primer combinations used allowed the identification of S-alleles in cultivars, as well as the indication of the most compatible pollinators. América and Santa Rosa cultivars, as well as Blood Plum, Wickson, Rosa Mineira, Estrela Púrpura, and Seleção 21 show total incompatibility among each other, since they share the same alleles.
\end{abstract}

Index terms: Prunus salicina, gametophytic self-incompatibility, S-RNase.

\section{Introdução}

Entre as espécies de clima temperado exploradas no Brasil, a ameixeira tem sido uma das frutíferas de maior difusão nos últimos anos, principalmente em razão do plantio de cultivares introduzidas ou selecionadas para melhor adaptação climática (Mota et al., 2010). Contudo, o volume produzido da fruta ainda é insuficiente para atender a demanda interna do país. Em 2011, o Brasil foi o quinto maior importador de ameixas, com um total de 39 mil toneladas (Food and Agriculture Organization of the United Nations, 2013).
A ameixeira japonesa (Prunus salicina Lindl.) predomina entre as espécies de ameixeira cultivadas no Brasil, pois encontra condições favoráveis para o seu cultivo (Seganfredo et al., 1995) e é mais adaptada às condições de inverno do Sul do país do que as ameixeiras europeias ( $P$. domestica $\mathrm{L}$.).

Mesmo com grande potencial de cultivo, alguns fatores têm limitado o aumento da produção nacional de ameixas, com destaque para a autoincompatibilidade reprodutiva do tipo gametofítica (Schifino-Wittmann \& Dall'Agnol, 2002; Raseira, 2003; Takayama \& Isogai, 2005). Dessa forma, para a formação de pomares de ameixeira japonesa, são necessárias cultivares 
polinizadoras compatíveis, cujo pólen deverá efetivamente fecundar o pistilo da cultivar produtora, caso contrário, não haverá produção de frutos.

No fenômeno de autoincompatibilidade gametofítica, o determinante feminino é uma ribonuclease (S-RNase) expressa no pistilo, onde as proteínas, localizadas principalmente na parte superior do estilete, atuam ao inibir ou degradar o RNA do tubo polínico que compartilha o mesmo alelo-S do pistilo (Mccubbin \& Kao, 2000; Schifino-Wittmann \& Dall'Agnol, 2002; Takayama \& Isogai, 2005; Zhang et al., 2009; Wu et al., 2013). Já o determinante do alelo-S do pólen é uma proteína F-box (SFB-S-haplotype-specific F-box) que geralmente atua como componente ligante da ubiquitina, envolvida em uma via de degradação proteica (Zhang et al., 2009), mediada pela ubiquitina de S-RNases de pólen oriundo de cruzamento (Takayama \& Isogai, 2005; Zhang et al., 2009; Gharesheikhbayat et al., 2011; Franceschi et al., 2012; Wu et al., 2013). Em uma situação de incompatibilidade, a S-RNase do pistilo degrada o RNA do pólen, o que impede o crescimento do tubo polínico (Zhang et al., 2009; McClure et al., 2011).

O sistema de autoincompatibilidade gametofítica apresenta três tipos de interação de compatibilidade: totalmente incompatível, quando ambos os alelos são comuns; parcialmente compatível, quando apenas um alelo é diferente; e totalmente compatível, quando os quatro alelos são diferentes (Kaufmann et al., 1992).

Além dos ensaios de polinização controlada em campo, a informação genética obtida sobre a incompatibilidade alélica pode ser utilizada no planejamento de estratégias de melhoramento, com hibridações controladas. Ela também pode auxiliar no desenho de pomares, o que garante uma eficiente polinização com uso de cultivares totalmente compatíveis (Albuquerque et al., 2011).

A caracterização de alelos-S, quando associada à tecnologia de transformação genética de plantas, poderá potencializar os trabalhos de melhoramento genético que visam a obtenção de cultivares autoférteis, com melhorias na frutificação efetiva e na produtividade.

O objetivo deste trabalho foi identificar e caracterizar molecularmente os alelos-S de cultivares de ameixeira japonesa e verificar a compatibilidade gametofítica entre estes.

\section{Material e Métodos}

O material vegetal utilizado para as análises constituiu-se de folhas jovens, completamente expandidas e sadias, obtidas de 18 cultivares de ameixeira japonesa (P. salicina): Pluma 7, Gulf Rubi, Blood Plum, Wickson, América, Santa Rosa, Rosa Mineira, Estrela Púrpura, Amarelinha, The First, Harry Pieckstone, Santa Rita, Seleção 16 (Rosa Mineira x América), Seleção A26 (Burbank), Seleção 21 (Seleção A26 x Estrela Púrpura), Seleção 19 (América x Amarelinha), Methley e Simka. As amostras foram coletadas na estação experimental da Embrapa Clima Temperado ( $\left.31^{\circ} 42^{\prime} \mathrm{S} ; 52^{\circ} 21^{\prime} \mathrm{W}\right)$, em 2011.

As análises foram realizadas no Laboratório de Fisiologia Molecular de Plantas, do Departamento de Botânica, do Instituto de Biologia, da Universidade Federal de Pelotas, RS. O DNA foi extraído a partir de amostras contendo $75 \mathrm{mg}$ de folhas jovens e frescas, tendo-se utilizado o método descrito por Doyle \& Doyle (1991), com quantificação em gel de agarose $0,8 \%$, uso do padrão DNA de fago lambda digerido com a enzima Hind III e subsequente diluição das amostras para concentração final de $5 \mathrm{ng} \mu \mathrm{L}^{-1}$.

Para cada uma das reações de PCR, as concentrações dos componentes foram: $20 \mathrm{ng}$ de DNA de cada amostra; PCR buffer $1 \mathrm{X}$; $1,5 \mathrm{mmol} \mathrm{L}^{-1}$ de $\mathrm{MgCl}_{2}$; $150 \mu \mathrm{mol} \mathrm{L}{ }^{-1}$ de cada dNTP; $0,4 \mu \mathrm{mol} \mathrm{L}^{-1}$ de cada

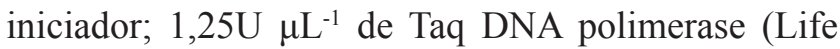
Technologies do Brasil Ltda., São Paulo, SP) e água Milli-Q para um volume final de $25 \mu \mathrm{L}$. Os iniciadores utilizados foram as combinações Pru- $\mathrm{C}_{2} / \mathrm{PCE}-\mathrm{R}$ (Tao et al., 1999; Yamane et al., 2001) e Pru- $\mathrm{C}_{2} /$ Pru-C $\mathrm{C}_{5}$ (Tao et al., 1999). As sequencias estão descritas na Tabela 1.

A amplificação do DNA foi realizada em termociclador PCR Sprint (Thermo Fisher Scientific Brasil Instrumentos de Processo Ltda., São Paulo, SP) com: perfil térmico inicial de $94^{\circ} \mathrm{C}$ por $5 \mathrm{~min}, 54^{\circ} \mathrm{C}$ por 2 min e $72^{\circ} \mathrm{C}$ por $3 \mathrm{~min}$; seguido de 35 ciclos de $94^{\circ} \mathrm{C}$

Tabela 1. Iniciadores utilizados para determinação dos alelos-S nas cultivares de ameixeira japonesa (Prunus salicina), com suas respectivas sequências de nucleotídeos.

\begin{tabular}{|c|c|}
\hline Designação do iniciador & Sequência (5'-3') \\
\hline Pru- $\mathrm{C}_{2}$ & CTA TGG CCA AGT AAT TAT TCA AAC C \\
\hline PCE-R & TGT TTG TTC CAT TCG CYT TCC C \\
\hline Pru-C $\mathrm{C}_{2}$ & CTA TGG CCA AGT AAT TAT TCA AAC C \\
\hline Pru- $\mathrm{C}_{5}$ & TAC CAC TTC ATG TAA CAA CTG AG \\
\hline
\end{tabular}

Pesq. agropec. bras., Brasília, v.48, n.10, p.1360-1367, out. 2013 DOI: 10.1590/S0100-204X2013001000007 
por $1 \mathrm{~min}, 54^{\circ} \mathrm{C}$ por $2 \mathrm{~min}, 72^{\circ} \mathrm{C}$ por $3 \mathrm{~min}$; e ciclo final de $94^{\circ} \mathrm{C}$ por $1 \mathrm{~min}, 54^{\circ} \mathrm{C}$ por $2 \mathrm{~min}$ e $72^{\circ} \mathrm{C}$ por $10 \mathrm{~min}$. Os fragmentos de DNA amplificados foram submetidos à eletroforese em gel de agarose a $2 \%$, a $5 \mathrm{~V} \mathrm{~cm}^{-1}$, tendo-se utilizado como padrão o marcador de massa molecular 100 pb (Ludwig Biotecnologia Ltda., Alvorada, RS).

\section{Resultados e Discussão}

O par de iniciadores que apresentou melhores resultados de amplificação foi Pru- $\mathrm{C}_{2} /$ Pru- $\mathrm{C}_{5}$, o que indicou amplificação de alelos nas 18 cultivares testadas (Figura 1). Cada cultivar apresentou dois alelos distintos, com exceção das cultivares Gulf Rubi, Amarelinha, Harry Pieckstone, Seleção 19 (América x Amarelinha) e Methley, que amplificaram apenas um alelo. O par de iniciadores Pru- $\mathrm{C}_{2} / \mathrm{PCE}-\mathrm{R}$ amplificou os alelos em apenas 13 cultivares testadas $(72,2 \%)$; destas, oito cultivares apresentaram dois alelos amplificados e cinco [Gulf Rubi, The First, Friar, Seleção A26 e Seleção 21 (Seleção A26 x Estrela Púrpura)] obtiveram apenas um único alelo (Figura 2).

Ao se comparar os produtos de PCR dos diferentes conjuntos de iniciadores (Pru- $\mathrm{C}_{2} /$ Pru- $\mathrm{C}_{5}$ com Pru- $\mathrm{C}_{2} /$ PCE-R), pôde-se observar que a reação de amplificação

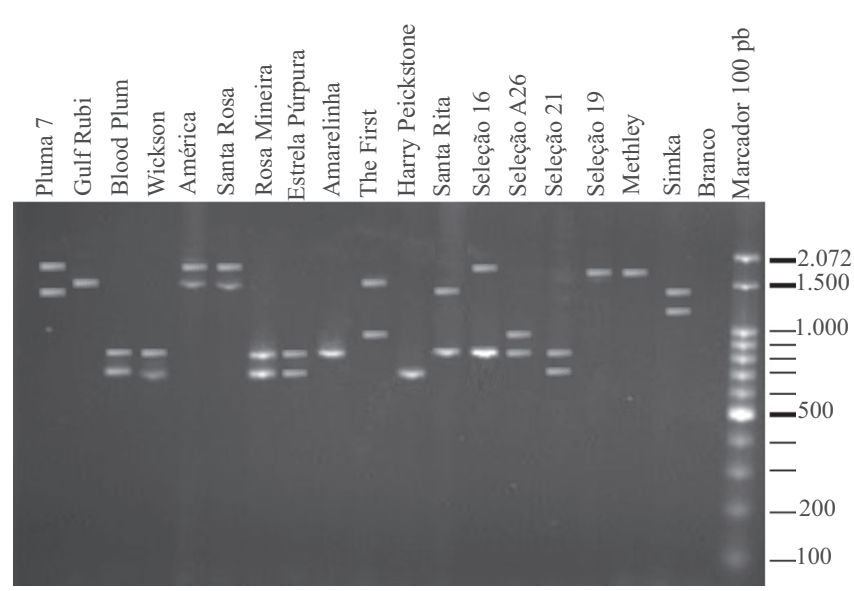

Figura 1. Amplificação por PCR de alelos $\mathrm{S}$ obtidos com a combinação de iniciadores Pru- $\mathrm{C}_{2} / \mathrm{Pru} \mathrm{C}_{5}$ das seguintes cultivares de ameixeira japonesa (Prunus salicina): Pluma 7, Gulf Rubi, Blood Plum, Wickson, América, Santa Rosa, Rosa Mineira, Estrela Púrpura, Amarelinha, The First, Harry Pieckstone, Santa Rita, Seleção 16 (Rosa Mineira X América), Seleção A26 (Burbank), Seleção 21 (Seleção A26 x Estrela Púrpura), Seleção 19 (América x Amarelinha), Methley e Simka. produziu fragmentos com tamanhos diferentes, resultantes das diferenças no número de nucleotídeos da sequência hipervariável interna aos pontos de ligação desses iniciadores em cada cultivar. Quando se utilizou o par de iniciadores Pru- $\mathrm{C}_{2} /$ Pru- $\mathrm{C}_{5}$, oito diferentes alelos foram identificados entre as 18 cultivares testadas. Estes alelos, conforme a visualização do resultado da amplificação, apresentaram tamanho entre 700 e 1.900 pb (Figura 1). Quando se utilizou o par de iniciadores Pru- $\mathrm{C}_{2} / \mathrm{PCE}-\mathrm{R}$, seis diferentes alelos foram amplificados; porém, o tamanho destes fragmentos foi menor do que o daqueles obtidos com o par de iniciadores anterior, que foi em torno de 550 a $1.500 \mathrm{pb}$ (Figura 2). Esse menor tamanho dos alelos ocorreu, pois o iniciador PCE-R ancora numa região intermediária entre Pru- $\mathrm{C}_{2}$ e Pru- $\mathrm{C}_{5}$ (Beppu et al., 2002).

Beppu et al. (2002), ao utilizar o par de iniciadores Pru- $\mathrm{C}_{2} / \mathrm{PCE}-\mathrm{R}$, obtiveram a amplificação de dois alelos em $P$. salicina, e nove diferentes alelos foram obtidos a partir de 17 cultivares avaliadas. No entanto, quando esses autores utilizaram o par de iniciadores Pru- $T_{2} /$ PCE-R, apenas uma cultivar apresentou a amplificação de um alelo, e as demais apresentaram os dois alelos.

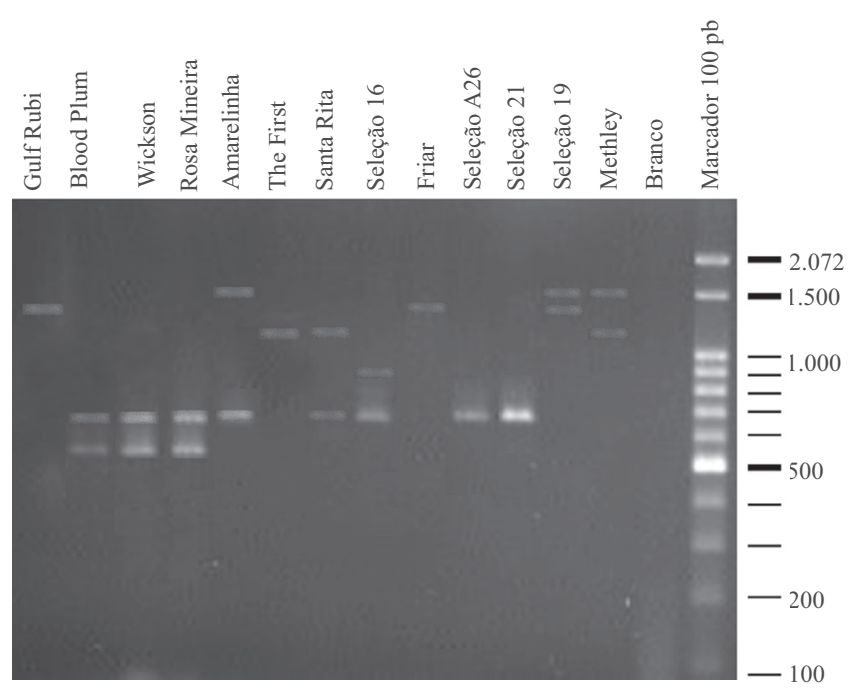

Figura 2. Amplificação por PCR de alelos $\mathrm{S}$ obtidos com a combinação de iniciadores $\mathrm{Pru}-\mathrm{C}_{2} / \mathrm{PCE}-\mathrm{R}$ das seguintes cultivares de ameixeira japonesa (Prunus salicina): Gulf Rubi, Blood Plum, Wickson, Rosa Mineira, Amarelinha, The First, Santa Rita, Seleção 16 (Rosa Mineira x América), Friar, Seleção A26 (Burbank), Seleção 21 (Seleção A26 x Estrela Púrpura), Seleção 19 (América x Amarelinha) e Methley. 
Em cultivares de damasqueiro japonês ( $P$. mume), Yaegaki et al. (2001) verificaram que o par de iniciadores Pru- $\mathrm{C}_{2} /$ Pru- $\mathrm{C}_{5}$ proporcionou a amplificação dos dois alelos nas seis cultivares estudadas. Porém, ao utilizaram o par de iniciadores Pru- $\mathrm{C}_{2} /$ Pru- $\mathrm{C}_{4}$, esses autores observaram a amplificação de dois alelos em apenas três das seis cultivares analisadas. De acordo com Kodad et al. (2008), a amplificação de apenas uma banda em algumas cultivares, quando utilizado iniciador para a região conservada $\left(\mathrm{C}_{1}-\mathrm{C}_{5}\right)$, é comum em amendoeira ( $P$. amygdalus), o que pode ser válido, também, para outras espécies sob análise.

A ausência de amplificação em algumas cultivares também foi constatada no presente trabalho, o que pode estar relacionado à presença de um alelo nulo para aquele loco gênico, ou à amplificação de bandas de mesmo tamanho, ou seja, o loco poderá estar em homozigose (Kodad et al., 2008; Chai et al., 2013). Alelos nulos são observados com frequência em locos de microssatélites, como resultado de mutações, que incluem, por exemplo, substituição, inserções e deleções em uma ou ambas as regiões de anelamento dos iniciadores (Callen et al., 1993; Chai et al., 2013; Sengupta et al., 2013).

A ausência de amplificação dos alelos-S também pode estar relacionada à capacidade dos iniciadores em amplificar esses alelos, o que implicaria na necessidade de desenvolvimento de iniciadores específicos para reconhecer com precisão os alelos-S presentes em cada cultivar ou genótipo (Donoso et al., 2009). Ercisli et al. (2012) utilizaram o par de iniciadores específicos $\mathrm{PaCons} / \mathrm{PaC}$ ConsII e obtiveram sucesso na amplificação dos dois alelos-S em cultivares de cereja ( $P$. avium), o que mostra a precisão na utilização de iniciadores específicos. Entretanto, esta especificidade poderia torná-los ineficientes para análise de outras cultivares, o que limitaria a identificação de apenas uma ou poucas cultivares.

Variações no número de alelos-S entre locos e a ausência de amplificação foram relatadas em algumas cultivares de ameixeira japonesa ( $P$. salicina) quando se utilizou o par de iniciadores IZ1/IZ4 (Mota et al., 2010). Estes iniciadores amplificam apenas sequências exclusivas de um alelo-S específico, ou seja, foram desenvolvidos especificamente para alguns alelos (Sapir et al., 2004), diferentemente do iniciador PCE-R, utilizado no presente trabalho, que apresenta pelo menos uma base degenerada para facilitar o anelamento.

Os resultados de PCR dos dois conjuntos de iniciadores utilizados para flanquear as regiões $\left(\mathrm{Pru}-\mathrm{C}_{2} /\right.$ PCE-R e Pru- $\mathrm{C}_{2} /$ Pru-C $\mathrm{C}_{5}$ ) mostraram tamanhos de fragmentos diferentes, porém com padrão semelhante de distribuição de bandas entre as cultivares (Figuras 1 e 2). Variações semelhantes foram obtidas por Beppu et al. (2002) e Mota et al. (2010).

Em relação à autoincompatibilidade, com base na amplificação com os dois pares de iniciadores testados, pôde-se obter informações sobre as plantas mais adequadas para serem usadas como polinizadoras. $\mathrm{Na}$ amplificação com os iniciadores Pru- $\mathrm{C}_{2} / \mathrm{Pru}-\mathrm{C}_{5}$, a cultivar América apresentou alelos de tamanho em torno de 1.900 e $1.500 \mathrm{pb}$, padrão semelhante ao de 'Santa Rosa' (Figura 1). As cultivares Blood Plum, Wickson, Rosa Mineira, Estrela Púrpura e Seleção 21 apresentaram alelos de tamanho em torno de 850 e $700 \mathrm{pb}$. Quando se utilizou os iniciadores Pru- $\mathrm{C}_{2} /$ PCE-R, as cultivares Blood Plum, Wickson e Rosa Mineira apresentaram alelos em torno de 650$550 \mathrm{pb}$ (Figura 2). Esses resultados sugerem que estas sete cultivares apresentam autoincompatibilidade; entre as 18 testadas, essas são as únicas com incompatibilidade total entre elas. Mota et al. (2010) também encontraram perfis eletroforéticos semelhantes nas cultivares Santa Rosa e América, o que está de acordo com os resultados de autoincompatibilidade e de amplificação obtidos no presente trabalho.

Algumas cultivares apresentaram compatibilidade parcial, com amplificação de dois alelos; contudo, apresentaram apenas um alelo em comum (Figuras 1 e 2). Cultivares que amplificaram dois alelos, mas nenhum alelo em comum, mostraram-se totalmente compatíveis entre si. As cultivares, que amplificaram apenas um alelo, podem ser consideradas de autoincompatibilidade parcial, como ocorreu com: Gulf Rubi, Amarelinha, Harry Pieckstone, Seleção 19 e Methley na amplificação com os iniciadores Pru- $\mathrm{C}_{2} /$ Pru- $\mathrm{C}_{5}$ (Tabela 2); e com Gulf Rubi, The First, Friar, Seleção A26 e Seleção 21 com o par de iniciadores Pru-C2/PCE-R (Tabela 3).

Embora o sequenciamento seja uma estratégia adequada para comprovar a identidade dos alelos-S, também é possível confirmá-la por meio da verificação da descendência dos alelos, ou seja, ao se confrontar o perfil eletroforético dos alelos de cada cultivar com 
seus respectivos genitores. No entanto, em algumas das cultivares utilizadas no presente trabalho, não se tem conhecimento dos genitores, o que não permite esse padrão de comparação.

Entre as cultivares estudadas, confirmou-se a descendência dos alelos da Seleção 16 (Rosa Mineira x América), a qual herdou um alelo de 'América' (1.900 pb) e outro de 'Rosa Mineira' (850 pb). A cultivar Seleção 21 (Seleção A26 x Estrela Púrpura) apresentou amplificação de dois alelos, dos quais um é herdado de 'Estrela Púrpura' (700 pb) e o outro, de 'Seleção A26' (850 pb) (Figura 1).

A cultivar Harry Pieckstone (Methley x Wickson) amplificou apenas um alelo herdado de 'Wickson'; porém, não ocorreu amplificação do segundo alelo, derivado de 'Methley'. A cultivar Seleção 19 (América $\mathrm{x}$ Amarelinha) também amplificou apenas um alelo, que, por estar em homozigose, não apresentou nem um

Tabela 2. Relação de compatibilidade gametofítica ${ }^{(1)}$ entre 18 cultivares de ameixeira japonesa (Prunus salicina) baseada na identificação dos alelos-S do loco Pru- $\mathrm{C}_{2} /$ Pru- $\mathrm{C}_{5}$, amplificados por PCR.

\begin{tabular}{|c|c|c|c|c|c|c|c|c|c|c|c|c|c|c|c|c|c|c|}
\hline \multirow[t]{2}{*}{ Cultivar } & \multicolumn{18}{|c|}{ Iniciadores Forward: Pru- $\mathrm{C}_{2}$ e Reverse: Pru- $\mathrm{C}_{5}$} \\
\hline & 1 & 2 & 3 & 4 & 5 & 6 & 7 & 8 & 9 & 10 & 11 & 12 & 13 & 14 & 15 & 16 & 17 & 18 \\
\hline Pluma 7 (1) & $\mathrm{AI}$ & $\mathrm{C}$ & $\mathrm{C}$ & $\mathrm{C}$ & $\mathrm{SC}$ & $\mathrm{SC}$ & $\mathrm{C}$ & $\mathrm{C}$ & $\mathrm{C}$ & $\mathrm{C}$ & $\mathrm{C}$ & $\mathrm{SC}$ & $\mathrm{SC}$ & $\mathrm{C}$ & $\mathrm{C}$ & $\mathrm{C}$ & $\mathrm{C}$ & $\mathrm{SC}$ \\
\hline Gulf Rubi (2) & & AIP & $\mathrm{C}$ & $\mathrm{C}$ & $\mathrm{SC}$ & $\mathrm{SC}$ & $\mathrm{C}$ & $\mathrm{C}$ & $\mathrm{C}$ & $\mathrm{SC}$ & $\mathrm{C}$ & $\mathrm{C}$ & $\mathrm{C}$ & $\mathrm{C}$ & $\mathrm{C}$ & $\mathrm{C}$ & $\mathrm{C}$ & $\mathrm{C}$ \\
\hline Blood Plum (3) & & & AI & I & $\mathrm{C}$ & $\mathrm{C}$ & I & I & $\mathrm{SC}$ & $\mathrm{C}$ & $\mathrm{SC}$ & $\mathrm{SC}$ & $\mathrm{SC}$ & $\mathrm{SC}$ & I & $\mathrm{C}$ & $\mathrm{C}$ & $\mathrm{C}$ \\
\hline Wickson (4) & & & & AI & $\mathrm{C}$ & $\mathrm{C}$ & I & I & $\mathrm{SC}$ & $\mathrm{C}$ & $\mathrm{SC}$ & $\mathrm{SC}$ & $\mathrm{SC}$ & $\mathrm{SC}$ & I & $\mathrm{C}$ & $\mathrm{C}$ & $\mathrm{C}$ \\
\hline América (5) & & & & & AI & I & $\mathrm{C}$ & $\mathrm{C}$ & $\mathrm{C}$ & $\mathrm{SC}$ & $\mathrm{C}$ & $\mathrm{C}$ & $\mathrm{SC}$ & $\mathrm{C}$ & $\mathrm{C}$ & $\mathrm{C}$ & $\mathrm{C}$ & $\mathrm{C}$ \\
\hline Santa Rosa (6) & & & & & & AI & $\mathrm{C}$ & $\mathrm{C}$ & $\mathrm{C}$ & $\mathrm{SC}$ & $\mathrm{C}$ & $\mathrm{C}$ & $\mathrm{SC}$ & $\mathrm{C}$ & $\mathrm{C}$ & $\mathrm{C}$ & $\mathrm{C}$ & $\mathrm{C}$ \\
\hline Rosa Mineira (7) & & & & & & & AI & I & $\mathrm{SC}$ & $\mathrm{C}$ & $\mathrm{SC}$ & $\mathrm{SC}$ & $\mathrm{SC}$ & $\mathrm{SC}$ & I & $\mathrm{C}$ & $\mathrm{C}$ & $\mathrm{C}$ \\
\hline Estrela Púrpura (8) & & & & & & & & AI & $\mathrm{SC}$ & $\mathrm{C}$ & $\mathrm{SC}$ & $\mathrm{SC}$ & $\mathrm{SC}$ & $\mathrm{SC}$ & I & $\mathrm{C}$ & $\mathrm{C}$ & $\mathrm{C}$ \\
\hline Amarelinha (9) & & & & & & & & & AIP & $\mathrm{C}$ & $\mathrm{C}$ & $\mathrm{SC}$ & $\mathrm{SC}$ & $\mathrm{SC}$ & $\mathrm{SC}$ & $\mathrm{C}$ & $\mathrm{C}$ & $\mathrm{C}$ \\
\hline The First (10) & & & & & & & & & & AI & $\mathrm{C}$ & $\mathrm{C}$ & $\mathrm{C}$ & $\mathrm{SC}$ & $\mathrm{C}$ & $\mathrm{C}$ & $\mathrm{C}$ & $\mathrm{C}$ \\
\hline Harry Pieckstone (11) & & & & & & & & & & & AIP & $\mathrm{C}$ & $\mathrm{C}$ & $\mathrm{C}$ & $\mathrm{SC}$ & $\mathrm{C}$ & $\mathrm{C}$ & $\mathrm{C}$ \\
\hline Santa Rita (12) & & & & & & & & & & & & AI & $\mathrm{SC}$ & $\mathrm{SC}$ & $\mathrm{SC}$ & $\mathrm{C}$ & $\mathrm{C}$ & $\mathrm{SC}$ \\
\hline Seleção 16 (13) & & & & & & & & & & & & & AI & $\mathrm{SC}$ & $\mathrm{SC}$ & $\mathrm{C}$ & $\mathrm{C}$ & $\mathrm{C}$ \\
\hline Seleção A26 (14) & & & & & & & & & & & & & & $\mathrm{AI}$ & $\mathrm{SC}$ & $\mathrm{C}$ & $\mathrm{C}$ & $\mathrm{C}$ \\
\hline Seleção 21 (15) & & & & & & & & & & & & & & & $\mathrm{AI}$ & $\mathrm{C}$ & $\mathrm{C}$ & $\mathrm{C}$ \\
\hline Seleção 19 (16) & & & & & & & & & & & & & & & & AIP & $\mathrm{SC}$ & $\mathrm{C}$ \\
\hline Methley (17) & & & & & & & & & & & & & & & & & AIP & $\mathrm{C}$ \\
\hline Simka (18) & & & & & & & & & & & & & & & & & & $\mathrm{AI}$ \\
\hline
\end{tabular}

${ }^{(1)} \mathrm{AI}$, autoincompatível; SC, semicompatível; C, compatível; I, incompatível; AIP, autoincompatibilidade parcial.

Tabela 3. Relação de compatibilidade gametofítica ${ }^{(1)}$ entre 13 cultivares de ameixeira japonesa (Prunus salicina) baseada na identificação dos alelos-S do loco Pru- $\mathrm{C}_{2} / \mathrm{PCE}-\mathrm{R}$, amplificados por PCR.

\begin{tabular}{|c|c|c|c|c|c|c|c|c|c|c|c|c|c|}
\hline \multirow[t]{2}{*}{ Cultivar } & \multicolumn{13}{|c|}{ Iniciadores Forward: Pru- $\mathrm{C}_{2}$ e Reverse: PCE R } \\
\hline & 1 & 2 & 3 & 4 & 5 & 6 & 7 & 8 & 9 & 10 & 11 & 12 & 13 \\
\hline Gulf Rubi (1) & AIP & $\mathrm{C}$ & $\mathrm{C}$ & $\mathrm{C}$ & $\mathrm{C}$ & $\mathrm{C}$ & $\mathrm{C}$ & $\mathrm{C}$ & $\mathrm{SC}$ & $\mathrm{C}$ & $\mathrm{C}$ & $\mathrm{SC}$ & $\mathrm{C}$ \\
\hline Blood Plum (2) & & AI & I & I & $\mathrm{SC}$ & $\mathrm{C}$ & $\mathrm{SC}$ & $\mathrm{SC}$ & $\mathrm{C}$ & $\mathrm{SC}$ & $\mathrm{SC}$ & $\mathrm{C}$ & $\mathrm{C}$ \\
\hline Wickson (3) & & & AI & I & $\mathrm{SC}$ & $\mathrm{C}$ & $\mathrm{SC}$ & $\mathrm{SC}$ & $\mathrm{C}$ & $\mathrm{SC}$ & $\mathrm{SC}$ & $\mathrm{C}$ & $\mathrm{C}$ \\
\hline Rosa Mineira (4) & & & & AI & $\mathrm{SC}$ & $\mathrm{C}$ & $\mathrm{SC}$ & $\mathrm{SC}$ & $\mathrm{C}$ & $\mathrm{SC}$ & $\mathrm{SC}$ & $\mathrm{C}$ & $\mathrm{C}$ \\
\hline Amarelinha (5) & & & & & AIP & $\mathrm{C}$ & $\mathrm{SC}$ & $\mathrm{SC}$ & $\mathrm{C}$ & $\mathrm{SC}$ & $\mathrm{SC}$ & $\mathrm{SC}$ & $\mathrm{SC}$ \\
\hline The First (6) & & & & & & AIP & $\mathrm{SC}$ & $\mathrm{C}$ & $\mathrm{C}$ & $\mathrm{C}$ & $\mathrm{C}$ & $\mathrm{C}$ & $\mathrm{SC}$ \\
\hline Santa Rita (7) & & & & & & & AI & $\mathrm{SC}$ & $\mathrm{C}$ & $\mathrm{SC}$ & $\mathrm{SC}$ & $\mathrm{C}$ & $\mathrm{SC}$ \\
\hline Seleção 16 (8) & & & & & & & & AI & $\mathrm{C}$ & $\mathrm{SC}$ & $\mathrm{SC}$ & $\mathrm{C}$ & $\mathrm{C}$ \\
\hline Friar (9) & & & & & & & & & AIP & $\mathrm{C}$ & $\mathrm{C}$ & $\mathrm{SC}$ & $\mathrm{C}$ \\
\hline Seleção A26 (10) & & & & & & & & & & AIP & $\mathrm{SC}$ & $\mathrm{C}$ & $\mathrm{C}$ \\
\hline Seleção 21 (11) & & & & & & & & & & & AIP & $\mathrm{C}$ & $\mathrm{C}$ \\
\hline Seleção 19 (12) & & & & & & & & & & & & AI & $\mathrm{SC}$ \\
\hline Methley (13) & & & & & & & & & & & & & AI \\
\hline
\end{tabular}

${ }^{(1)}$ AI, autoincompatível; SC, semicompatível; C, compatível; I, incompatível; AIP, autoincompatibilidade parcial. 
dos alelos dos seus genitores. Este fato por ter ocorrido em razão da não amplificação de um dos alelos de 'América', ou, então, da possível contaminação com pólen de outra cultivar na hora da polinização.

A análise dos alelos-S e da genealogia tem permitido a predição dos genótipos S-RNase de cultivares, a identificação de possíveis relações genéticas e especulações sobre a origem de alguns alelos que codificam S-RNases. Com a identificação dos alelos-S, foi possível estabelecer uma nova relação de polinizadoras para as cultivares estudadas, tendo-se determinado algumas delas por métodos convencionais de polinização e testes de crescimento do tubo polínico (Tabela 4). Nesta nova relação, somente foram utilizadas as cultivares que mostraram compatibilidade completa.

Vale ressaltar que, além dos dados de compatibilidade reprodutiva por meio de análises moleculares, deve-se levar em consideração a variabilidade das condições climáticas, principalmente em relação à temperatura $\mathrm{e}$ à época de floração, consideradas pontos-chave para uma ótima frutificação efetiva, mesmo se houver compatibilidade molecular.

A identificação dos alelos S-RNase permitiu a atribuição das cultivares de ameixeira japonesa aos seus correspondentes grupos de compatibilidade; esta informação é valiosa para a seleção de genótipos, para programas de melhoramento genético e para seleção adequada de cultivares polinizadoras em pomares comerciais. A seleção baseada somente na coincidência, parcial ou total, no período de floração não é suficiente para escolher com precisão as melhores cultivares polinizadoras. Mesmo cultivares distintas que apresentam épocas de floração completamente coincidentes não garantem frutificação efetiva se não houver compatibilidade dos alelos-S.

Tabela 4. Relação de cultivares de ameixeira japonesa (Prunus salicina) e suas polinizadoras estabelecidas a partir das análises de compatibilidade dos alelos-S amplificados por PCR.

\begin{tabular}{|c|c|c|}
\hline Cultivares produtoras & $\begin{array}{l}\text { Cultivares polinizadoras } \\
\text { tradicionais }\end{array}$ & $\begin{array}{l}\text { Cultivares polinizadoras (indicadas } \\
\text { a partir de dados moleculares) }\end{array}$ \\
\hline Pluma 7 & Blood Plum e Amarelinha & $\begin{array}{l}\text { Gulf Rubi, Blood Plum, Wickson, Rosa Mineira, Estrela Púrpura, Amarelinha, The First, } \\
\text { Harry Pieckstone, Seleção A26, Seleção 21, Seleção 19, Methley. }\end{array}$ \\
\hline Gulf Rubi & - & $\begin{array}{l}\text { Pluma 7, Blood Plum, Wickson, Rosa Mineira, Estrela Púrpura, Amarelinha, Harry Pieckstone, } \\
\text { Santa Rita, Seleção 16, Seleção A26, Seleção 21, Methley, Simka. }\end{array}$ \\
\hline Blood Plum & - & Pluma 7, Gulf Rubi, América, Santa Rosa, The First, Friar, Seleção 19, Methley, Simka. \\
\hline Wickson & - & Pluma 7, Gulf Rubi, América, Santa Rosa, The First, Friar, Seleção 19, Methley, Simka. \\
\hline América & Reubennel e Rosa Mineira & $\begin{array}{l}\text { Blood Plum, Wickson, Rosa Mineira, Estrela Púrpura, Amarelinha, Harry Pieckstone, } \\
\text { Santa Rita, Friar, Seleção A26, Seleção 21, Seleção 19, Methley, Simka. }\end{array}$ \\
\hline Santa Rosa & Santa Rita, The First e Wickson & $\begin{array}{l}\text { Blood Plum, Wickson, Rosa Mineira, Estrela Púrpura, Amarelinha, Harry Pieckstone, } \\
\text { Santa Rita, Friar, Seleção A26, Seleção 21, Seleção 19, Methley, Simka. }\end{array}$ \\
\hline Rosa Mineira & Relativa autofertilidade & Pluma 7, Gulf Rubi, América, Santa Rosa, The First, Friar, Seleção 19, Methley, Simka. \\
\hline Estrela Púrpura & - & Pluma 7, Gulf Rubi, América, Santa Rosa, The First, Friar, Seleção 19, Methley, Simka. \\
\hline Amarelinha & Blood Plum, Pluma 7 e Friar & $\begin{array}{c}\text { Pluma 7, Gulf Rubi, América, Santa Rosa, The First, Harry Pieckstone, } \\
\text { Friar, Seleção 19, Methley, Simka. }\end{array}$ \\
\hline The First & Santa Rita, Santa Rosa e Methley & $\begin{array}{l}\text { Pluma 7, Blood Plum, Wickson, Rosa Mineira, Estrela Púrpura, Amarelinha, Harry Pieckstone, } \\
\text { Santa Rita, Friar, Seleção 21, Seleção 16, Seleção 19, Simka. }\end{array}$ \\
\hline Harry Pieckstone & Wade e Wickson & $\begin{array}{c}\text { Pluma 7, Gulf Rubi, América, Santa Rosa, Amarelinha, The First, Santa Rita, Seleção 16, } \\
\text { Seleção A26, Seleção 19, Methley, Simka. }\end{array}$ \\
\hline Santa Rita & Santa Rosa, Methley e The First & Gulf Rubi, América, Santa Rosa, The First, Harry Pieckstone, Friar, Seleção 19, Methley. \\
\hline Seleção 16 & - & Gulf Rubi, The First, Harry Pieckstone, Seleção 19, Methley, Simka, Friar. \\
\hline Friar & - & $\begin{array}{c}\text { Blood Plum, Wickson, Rosa Mineira, Amarelinha, The First, Santa Rita, Seleção 16, } \\
\text { Seleção A26, Seleção 21, Methley. }\end{array}$ \\
\hline Seleção A26 & - & Pluma 7, Gulf Rubi, América, Santa Rosa, Harry Pieckstone, Seleção 19, Methley, Simka. \\
\hline Seleção 21 & - & Pluma 7, Gulf Rubi, América, Santa Rosa, The First, Seleção 19, Methley, Friar, Simka. \\
\hline Seleção 19 & - & $\begin{array}{l}\text { Pluma 7, Blood Plum, Wickson, América, Santa Rosa, Rosa Mineira, Estrela Púrpura, The First, } \\
\text { Harry Pieckstone, Santa Rita, Seleção 16, Amarelinha, Seleção A26, Seleção 21, Simka. }\end{array}$ \\
\hline Methley & - & $\begin{array}{l}\text { Pluma 7, Gulf Rubi, Blood Plum, Wickson, América, Santa Rosa, Rosa Mineira, Estrela Púrpura, } \\
\text { The First, Harry Pieckstone, Santa Rita, Seleção 16, Seleção A26, Seleção 21, Simka. }\end{array}$ \\
\hline Simka & - & $\begin{array}{l}\text { Gulf Rubi, Blood Plum, Wickson, América, Santa Rosa, Rosa Mineira, Estrela Púrpura, } \\
\text { Amarelinha, The First, Harry Pieckstone, Seleção 16, Seleção A26, } \\
\text { Seleção 21, Seleção 19, Methley. }\end{array}$ \\
\hline
\end{tabular}




\section{Conclusões}

1. As combinações de iniciadores, bem como as condições de PCR utilizadas, permitem a efetiva caracterização de alelos-S nas cultivares de Prunus salicina estudadas, o que possibilita a seleção de cultivares compatíveis reprodutivamente.

2. As cultivares América e Santa Rosa, bem como Blood Plum, Wickson, Rosa Mineira, Estrela Púrpura e Seleção 21, apresentam incompatibilidade total entre si.

\section{Agradecimentos}

Ao Conselho Nacional de Desenvolvimento Científico e Tecnológico (CNPq), à Coordenação de Aperfeiçoamento de Pessoal de Nível Superior (Capes) e à Fundação de Amparo à Pesquisa do Estado do Rio Grande do Sul (Fapergs), pela concessão das bolsas de pesquisa e pelo apoio financeiro.

\section{Referências}

ALBUQUERQUE JUNIOR, C.L. de; DENARDI, F.; DANTAS, A.C.M.; DENARDI, F. The self-incompatible RNase S-alleles of Brazilian apple cultivars. Euphytica, v.181, p.277-284, 2011. DOI: 10.1007/s10681-011-0431-0.

BEPPU, K.; YAMANE, H.; YAEGAKI, H.; YAMAGUCHI, M.; KATAOKA, I.; TAO, R. Diversity of S-RNase genes and S-haplotypes in Japanese plum (Prunus salicina Lindl.). Journal of Horticultural Science and Biotechnology, v.77, p.658-664, 2002.

CALLEN, D.F.; THOMPSON, A.D.; SHEN, Y.; PHILLIPS, H.A.; RICHARDS, R.I.; MULLEY, J.C.; SUTHERLAND, G.R. Incidence and origin of "null" alleles in the (AC)n microsatellite markers. American Journal of Human Genetics, v.52, p.922-927, 1993.

CHAI, L.; BISWAS, M.K.; YI, H.; GUO, W.; DENG, X. Transferability, polymorphism and effectiveness for genetic mapping of the Pummelo (Citrus grandis Osbeck) EST-SSR markers. Scientia Horticulturae, v.155, p.85-91, 2013. DOI: 10.1016/j.scienta.2013.02.024.

DONOSO, J.M.; AROS, D.; MENESES, C.; INFANTE, R. Identification of S-alleles associated with self-incompatibility in apricots (Prunus armeniaca L.) using molecular markers. Journal of Food Agriculture and Environment, v.7, p.270-273, 2009.

DOYLE, J.J.; DOYLE, J.L. Isolation of plant DNA from fresh tissue. Focus, v.1, p.13-15, 1991.

ERCISLI, S.; RADUNIC, M.; GADZE, J.; IPEK, A.; SKALJAC, M.; CMELIK, C. S-RNase based S-genotyping of Croatian sweet cherry (Prunus avium L.) genotypes. Scientia Horticulturae, v.139, p.21-24, 2012. DOI: 10.1016/j.scienta.2012.02.041.
FOOD AND AGRICULTURE ORGANIZATION OF THE UNITED NATIONS. FaoStat. Available at: <http://faostat.fao.org/ site/342/default.aspx $>$. Accessed on: 8 Nov. 2013.

FRANCESCHI, P.; DONDINI, L.; SANZOL, J. Molecular bases and evolutionary dynamics of self-incompatibility in the Pyrinae (Rosaceae). Journal of Experimental Botany, v.63, p.4015-4032, 2012. DOI: $10.1093 /$ jxb/ers 108 .

GHARESHEIKHBAYAT, R.; DONDINI, L.; SANSAVINI, S. Identification of self-incompatibility allels in apricot (Prunus armeniaca L.) using multi-level approaches. Seed and Plant Improvement Journal, v.27, p.426-411, 2011.

KAUFMANN, H.; KIRCH, H.; WEMMER, T.; PEIL, A.; LOTTSPEICH, F.; UHRIG, H.; SALAMINI, F., THOMPSON, R. Sporophytic and gametophytic self-incompatibility. Sexual Plant Reproduction, v.4, p.115-125, 1992. DOI: 10.1007/978-3-642-77677-9_11.

KODAD, O.; SÁNCHEZ, A.; SAIBO, N.; OLIVEIRA, M.; SOCIAS, R.; COMPANY, R.S. Identification and characterization of new S-alleles associated with self-incompatibility in almond. Plant Breeding, v.127, p.632-638, 2008. DOI: 10.1111/j.1439-0 523.2008.01541.x.

MCCLURE, B.; CRUZ-GARCÍA, F.; ROMERO, C. Compatibility and incompatibility in S-RNase-based systems. Annals of Botany, v.108, p.647-658, 2011. DOI: 10.1093/aob/mcr179.

MCCUBBIN, A.G.; KAO, T.-H. Molecular recognition and response in pollen and pistil interactions. Annual Review of Cell and Developmental Biology, v.16, p.333-364, 2000. DOI: 10.1146/annurev.cellbio.16.1.333.

MOTA, M.S.; BIANCHI, V.J.; CARVALHO, A.Z. de; BRAGA, E.J.B.; PETERS, J.A. Caracterização molecular dos alelos-S de incompatibilidade gametofítica em Prunus salicina Lindl. Revista Brasileira de Fruticultura, v.32, p.798-807, 2010. DOI: 10.1590/ S0100-29452010005000096.

RASEIRA, M.C.B. Polinização. In: CASTRO, L.A.S. de (Ed.). Ameixa: produção. Brasília: Embrapa Informação Tecnológica, 2003. p.30-33.

SAPIR, G.; STERN, R.A.; EISIKOWITCH, D.; GOLDWAY, M. Cloning of four new Japanese plum S-alleles and determination of the compatibility between cultivars by PCR analysis. Journal of Horticultural Science and Biotechnology, v.79, p.223-227, 2004.

SCHIFINO-WITTMANN, M.T.; DALL'AGNOL, M. Auto-incompatibilidade em plantas. Ciência Rural, v.32, p.1083-1090, 2002. DOI: 10.1590/S0103-84782002000600027.

SEGANFREDO, R.; NACHTIGAL, J.C.; KERSTEN, E. Influência do ácido indolbutírico e de épocas de coleta de estacas no enraizamento de cultivares de ameixeira (Prunus salicina Lind1.). Revista Brasileira de Agrociência, v.1, p.40-42, 1995.

SENGUPTA, S.; DAS, B.; PRASAD, M.; ACHARYYA, P.; GHOSE, T.K. A comparative survey of genetic diversity among a set of Caricaceae accessions using microsatellite markers. SpringerPlus, v.2, 2013. DOI: 10.1186/2193-1801-2-345.

TAKAYAMA, S.; ISOGAI, A. Self-incompatibility in plants. Annual Review of Plant Biology, v.56, p.467-489, 2005. DOI: 10.1146/annurev.arplant.56.032604.144249. 
TAO, R.; YAMANE, H.; SUGIURA, A. Molecular typing of $\mathrm{S}$-alleles through identification, characterization and cDNA cloning for S-RNases in sweet cherry. Journal of the American Society for Horticulture Science, v.124, p.224-233, 1999.

WU, J.; GU, C.; KHAN, M.A.; WU, J.; GAO, Y.; WANG, C.; KORBAN, S.; ZHANG, S. Molecular determinants and mechanisms of gametophytic self-incompatibility in fruit trees of Rosaceae. Critical Reviews in Plant Sciences, v.32, p.53-68, 2013. DOI: 10.1080/07352689.2012.715986.

YAEGAKI, H.; SHIMADA, T.; MORIGUCHI, T.; HAYAMA, H.; HAJI, T.; YAMAGUCHI, M. Molecular characterization of
S-RNase genes and S-genotypes in the Japanese apricot (Prunus mume Sieb. et Zucc.). Sexual Plant Reproduction, v.13, p.251-257, 2001. DOI: 10.1007/s004970100064.

YAMANE, H.; TAO, R.; SUGIURA, A.; HAUCK, N.R.; IEZZONI, A.F. Identification and characterization of $S$-RNases in tetraploid sour cherry (Prunus cerasus L.). Journal of the American Society for Horticultural Science, v.126, p.661-667, 2001.

ZHANG, Y.; ZHAO, Z.; XUE, Y. Roles of proteolysis in plant self-incompatibility. Annual Review of Plant Biology, v.60, p.21-42, 2009. DOI: 10.1146/annurev.arplant.043008.092108.

Recebido em 21 de fevereiro de 2013 e aprovado em 23 de setembro de 2013 